\title{
Establishing a Successful Home Dialysis Program
}

\author{
Jose A. Diaz-Buxo Terri L. Crawford-Bonadio Donna St. Pierre \\ Katherine M. Ingram \\ Fresenius Medical Care - North America, Lexington, Mass., USA
}

\section{Key Words}

Peritoneal dialysis · Home hemodialysis · End-stage renal disease education

\begin{abstract}
The renewed interest in home dialysis therapies makes it pertinent to address the essentials of establishing and running a successful home dialysis program. The success of a home program depends on a clear understanding of the structure of the home program team, the physical plant, educational tool requirements, reimbursement sources and a business plan. A good command of the technical and economic aspects is important, but the primary drivers for the creation and growth of a home dialysis program are the confidence and commitment of the nephrological team.
\end{abstract}

Copyright @ 2006 S. Karger AG, Basel

In the absence of established science and formal guidelines on the creation and management of a successful home program, the best substitute is to analyze the commonalities of successful program practices. The general principles discussed here are universally practiced, but important local variations must be observed based on reimbursement for specific therapies, availability of services and personnel, and cultural differences. The preservation of individual freedoms and the opportunity to selfadminister peritoneal dialysis (PD) or home hemodialysis (HD) in the patient's own environment is at the heart of the home program initiative. Moving the patients from

\section{KARGER \\ Fax +41613061234 \\ E-Mail karger@karger.ch}

www.karger.com
(C) 2006 S. Karger AG, Basel

0253-5068/06/0241-0022\$23.50/0

Accessible online at: www.karger.com/bpu the controlled environment of the dialysis center to their home removes tremendous boundaries and shifts the accountability from healthcare providers to the patient. These circumstances significantly alter the dynamics of patient care. With the exception of the nursing home environment and HD centers, there are few other examples of therapeutic environments where care is essentially controlled by the healthcare team. Despite the obvious advantages of home dialysis, it is recognized that many patients are unable or unwilling to perform dialysis at home regardless of our efforts. Many patients must remain in the center for lack of a safe home environment, a partner, intellect, physical and psychological disabilities or extreme poverty. We will focus our attention on the components required to establish an efficient and successful home program and the tools to facilitate this process.

\section{The Nephrological Team}

Home dialysis is a team effort where each member is essential for the success of this enterprise. It is the responsibility of the team to address the patients' medical and psychological needs, improve their understanding of the disease process and provide the required treatments to facilitate self-participation in the treatment program. The driver of this initiative is the nephrologist. Behind every successful home program there is a nephrologist dedicated to support the nurses, provide education and market the home philosophy. The nephrologist must devote sufficient time for overseeing the planning, organization and direction of the program and be committed to mak- 
ing it work. The physician plays an active role in empowering the patient with therapy selection. Nephrologists must work together with their local administration to ensure adequate infrastructure, staffing to train and care for patients, and adequate training of the staff per regulatory guidelines. Unless the physician supports home therapies, the program is unlikely to grow or thrive.

The nurse holds all the activities of the home program together and nurtures its growth. The minimum staffing required to maintain a seamless operation, regardless of the size of the program, are two nurses: one dedicated to home training and a back-up nurse to fill in when the fulltime nurse is absent. The nurse in the key position acts as a liaison with other members of the team to ensure continuous care and coordination. The central role of the nurse is to teach the patients to perform dialysis and manage their renal disease at home. The ideal candidate should be a skilled caregiver, an enthusiastic teacher, someone who enjoys the rewards associated with helping chronically ill patients live comfortably and independently, and is comfortable evaluating, trouble-shooting and counseling patients personally and over the phone.

Dietitians, social workers, surgeons and other health professionals support, fine-tune and complete patient care management. Some of the roles change according to the program structure, culture and history. The Center for Medicare and Medicaid Services in the US and similar organizations in other countries mandate that each home program establishes a multi-disciplinary team of healthcare professionals. This team works together with patients and their families to understand the different modes of treatment available, how to adhere to the prescribed treatment, modify the diet and medications to individual needs, address psychosocial aspects of end-stage renal disease (ESRD) and to manage insurance and financial issues.

There are remarkable regional differences in the roles played by various health professionals. This is particularly true for social workers and training nurses. The specific roles are often dictated by the individual's personality and skills, availability, local regulations and evolution of the program. Generally speaking, social workers are charged with the evaluation and documentation of the patient's psychosocial status, assisting patients in achieving and maintaining optimal functional levels, providing financial counseling and facilitating satisfaction surveys. Registered dietitians are an integral part of the team. Their principal responsibilities are the initial and ongoing nutritional assessment, the provision of education and tools for diet management and active participation during the care planning meetings.
Table 1. Effect of pre-dialysis education on modality selection

\begin{tabular}{|c|c|c|c|}
\hline Source & Date & Patients & $\begin{array}{l}\text { Patients } \\
\text { choosing PD, } \%\end{array}$ \\
\hline Ahlmen et al. [1] & 1993 & 60 & 62 \\
\hline Prichard [2] & 1996 & 74 & 50 \\
\hline Levin et al. ${ }^{1}$ [3] & 1997 & 37 & 53 \\
\hline Levin et al. ${ }^{2}[3]$ & 1997 & 134 & 66 \\
\hline Lameire et al. [4] & 1997 & NA & 70 \\
\hline Little et al. [5] & 2001 & 254 & 45 \\
\hline FMC-NA [6] & 2001 & 386 & 51 \\
\hline Stack [7] & 2002 & 2,435 & $-{ }^{2}$ \\
\hline Wuerth et al. [8] & 2002 & 40 & 83 \\
\hline
\end{tabular}

NA $=$ Not assessed

${ }^{1}$ Vancouver study.

2 Toronto study.

The surgeon plays varying roles according to the needs and established relations with the center. The skill set of the nephrologist is a factor in determining who creates peritoneal access. However, even when catheters are mostly inserted by nephrologists, the involvement of a surgeon who knows the renal population, who is familiar with the comorbidities and complications of ERSD and is accountable for the outcomes of the program, is key to the success of the home program.

\section{Recruitment of Patients}

There is overwhelming evidence showing that when patients are given a choice through proper education before the start of dialysis, a significant proportion elect home dialysis over center dialysis (table 1) [1-8]. The results are similar around the world, regardless of any other influences. The decision should always be made by the patient and his family with the input of the medical team. Unfortunately, this is not always the case. Two factors are essential to empower the patient to make a judicious and well-informed decision: early and appropriate referral to a nephrologist and adequate education on therapeutic options. For the latter, there are a number of excellent, wellestablished tools available to nephrologists and other practitioners to help their patients understand and accept their illness. In some ways, we may consider education and planning more important than early referral to dialysis. In a recent study, planned dialysis defined as selection of PD or creation of a vascular access at the time of initiation of 


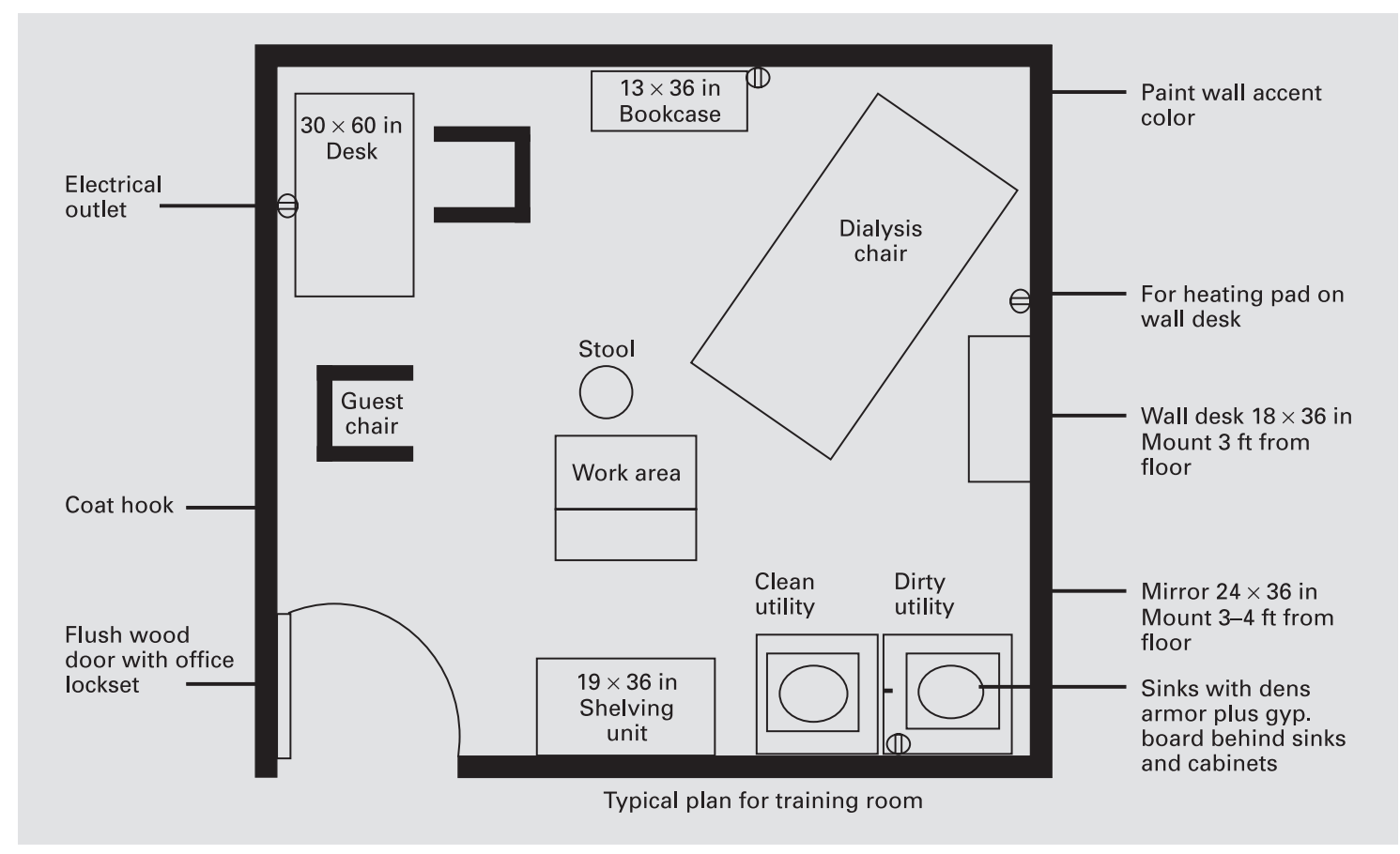

Fig. 1. Typical floor plan for a home dialysis training room.

dialysis strongly correlated with pre-ESRD education $(\mathrm{p}=$ $0.003)$, the creation of an arteriovenous fistula $(p=0.001)$ and selection of PD $(p=0.001)$ [9]. This pre-ESRD education provides the foundation to help patients cope with the emotional stress of their illness and gives them some of the tools necessary to select the dialysis modality best suited to their medical needs and lifestyle. Excellent pre-ESRD education programs focusing on therapy options specially designed for patients and their families are globally available through the Internet (www.kidneyoptions.com, www. kidney.org, www.homedialysiscentral.com).

Physician education and bias, or how well the physician understands the therapy and how comfortable he or she feels prescribing it, critically impacts recruitment. In the absence of significant medical contraindications and a lack of social support, a motivated patient should have access to home dialysis.

\section{Physical Plant}

Home training facilities do not require a lot of space, but must be designed for adequate supply storage, a safe, comfortable setting for patient training and performance of clinical procedures. Whilst space requirements may be minimal at first, planned expansion will save effort and resources.

The ideal training room provides privacy, limited distraction and the necessary training aids (fig. 1). There should be a designated 'clean/dirty' area for hand washing, disposal of body fluids and microbiological cultures. This area must be accessible to the patients so they will learn the process of handling biological waste. Part of the training area or waiting room may double as a resource room where patients can view educational videotapes, read or practice procedures. A home program of 15-20 patients will generally require fifty square feet for stocking inventory and equipment which may or may not be part of or near the training area. Office space must provide a private area for patient and staff consultations, patient charting and telephone follow-up calls. Administrative staff, if any, should be ideally located close to the medical records.

\section{On-Call Support}

Continuous and prompt support is essential to the provision of optimal home services. The very nature of the relation between the patient and the nephrological team requires a flawless flow of information on demand. The 
result of rapid and accurate responses improves patient outcomes, prevents waste of resources (by reducing unnecessary use of emergency services) and maximizes patient satisfaction. This service is traditionally provided by nurses. Unfortunately, with the exception of very large home programs with many trainers, the nurse on call is seldom familiar with the patient's case. Thus, the access to medical records is essential. Some successful programs have joint efforts with other area centers to offer on-call support services by telephone or e-mail. This initiative allows rotation of call duties and increases the pool of available experienced personnel.

\section{Policies and Procedures}

Professional resources to develop appropriate clinical policies and procedures are available through industry providers and renal organizations. Most of these materials can be adopted in their entirety or adapted to meet the specific needs of the center. Networking with other professionals who have demonstrated an ability to develop a well-run home program and actual site visits to centers of excellence to obtain suggestions and guidance are also helpful. Procedures for use of specific products are available from the manufacturers.

\section{Patient Training and Education}

An effective patient training program enables home patients to take control of their therapy and lives. The training process begins with an assessment of the patient's health and ability to adhere to the disciplines of home therapy. Different reimbursement scales and regulatory policies govern the training process in different countries. It is imperative to obtain the latest guidelines for your specific country or province and become thoroughly familiar with its contents in order to plan the length of training. In the US, the Physician's Guide to Medicare Coverage of Kidney Dialysis and Kidney Transplant Services is available from the Center for Medicare and Medicaid Services. Similar publications are available in other countries.

The determination of whether the training process has reached a reasonable conclusion should be made jointly by the patient and the multi-disciplinary team. Each program must formally assess the patient's competence in performing the dialysis procedures in a safe and effective manner and provide certification of such achievement.
Sample tests and training checklists are available from various professional organizations and manufacturers.

\section{Professional Education}

In the US, nephrology training programs generally do not offer trainees sufficient exposure to care for HD and PD patients. The results of a survey conducted by Mehrotra et al. [10] showed that $29 \%$ of US training programs had less than 5 PD patients per fellow, and there were wide variations in the amount of time trainees spent caring for $\mathrm{HD}$ and $\mathrm{PD}$ patients. In 14\% of training programs, fellows spent less than 5\% of their time receiving training for patients undergoing PD. A poll of second year nephrology fellows in the US $(n=67)$ revealed that $50 \%$ were from programs offering 3 or fewer months of exposure to outpatient HD and 25\% reported no exposure to PD [11]. Furthermore, 25\% reported no formal rounds with an attending nephrologist on dialysis patients. If nephrologists are to take their appropriate place as leaders of the care delivery team, nephrology fellowships must be restructured with appropriate emphasis placed on the comprehensive care of ESRD and chronic kidney disease patients. In countries where home dialysis is not being offered or with very low rates of utilization, one would not expect any training or expertise among physicians in training, thus adding physician bias due to lack of expertise and confidence to the list of deterrents to home dialysis. Professional education programs have been developed to meet these demands for both physicians and nurses. The Advanced Renal Education Program ${ }^{\mathrm{TM}}$ is an example of a comprehensive core curriculum on PD and home HD offered to healthcare professionals by an international faculty [12]. Other programs are available dedicated to either PD or frequent home HD.

\section{Cost of Home Therapies to Society}

A meta-analysis of 13 studies calculated the cost effectiveness of home dialysis compared with in-center dialysis [13]. The annual cost of home therapies was significantly lower (USD 33,000-55,000) compared with in-center therapies (USD 55,000-80,000). The United States Renal Data System data for 2003 reported a cost advantage of PD over in-center HD of USD 13,687 per year [14]. There may be significant differences in the cost of training between PD and home HD during the first year due to the longer period of training required for 
Table 2. Sources of home program operational costs

\begin{tabular}{llll}
\hline Facility operations & Personnel costs & Equipment & Overhead \\
\hline Rent & Medical director & Furniture & Supply company \\
Insurance & Training clinicians & Information technology & Materials management \\
Utilities & Social worker & Medical equipment & Administrative costs and insurance \\
Maintenance & Dietitian & Products & Educational programs \\
& Clerk & Ancillary items & Accounts payable \\
& & Accounts receivable \\
& & Medical billing \\
\hline
\end{tabular}

$\mathrm{HD}$, resulting in 1 full-time equivalent nurse training three times more PD patients than HD patients, the local cost of solutions and disposables for PD and HD, respectively, and the frequency of treatment during training. The lower reported cost for home therapies combined with the contributions resulting from the increased productivity of this cohort (since more home patients are employed) translates into markedly lower total cost to society.

\section{Economic and Regulatory Considerations}

The economic and regulatory issues are country specific and quite variable. Home patients tend to be healthier and more compliant and avoid hospital stays at all costs which is beneficial to the program economics and reduces cost to society. Furthermore, home patients are more likely to have employer group health plans (EGHPs) than in-center patients [15]. In the US, EGHPs contribute more than three times the prevalent Medicare rate. Consequently, although only $25 \%$ of patients have EGHP primary coverage, this insurance provides $50 \%$ of dialysis clinic revenues across the country [16]. The principal sources of operational costs for home programs are summarized in table 2 . The relative cost of each category very much depends on the size of the program and the already existing resources of the parent organization. The major types of reimbursement are through public and private insurance or a combination of both. Adding to the complexity of reimbursement, several systems are often prevalent in the same country. Furthermore, the coverage may vary as to specific modalities of therapy (e.g., continuous ambulatory peritoneal dialysis only, home HD, but no PD), the location where training is provided (e.g., hospital, physician's office, free-standing unit), the choice of facility and physician, and the types of medications and services such as transportation and paid assistants (relatives versus professional aides).

In some ways, the reimbursement structure may be considered the ultimate controlling force in the establishment and maintenance of home dialysis. Ironically, it is the low reimbursement for dialysis in general that has stimulated the use of home dialysis in certain countries, while that same lack of funding is considered to be the deterrent of growth in other countries. Nonetheless, adequate reimbursement is not the only driver for home therapies as confirmed by the lack of growth of the home population in countries with special reimbursement for home dialysis. On the bright side, there is interest in revising reimbursement to favor home and frequent therapies in various countries such as the UK, where the Ministry of Health has encouraged the consideration of such therapies, and the US, where a recently introduced bill to Congress (HR-3096, Kidney Patient More Frequent Dialysis Quality Act of 2005) requests payments for more frequent HD, whether daily, nightly or more frequent, done at home or in the facility.

\section{'The Proverbial 20 Patients'}

A critical number of patients is required to justify the aforementioned dedicated personnel, infrastructure and administrative expenses. Extensive experience and various business models suggest that approximately 20 patients are required to keep the program profitable. Thus, when starting a program, the team must be aware of the initial negative economic impact, the importance of early growth and the potential limitations and compromises required. Patient and staff retention are essential during these early stages. Continuous quality initiatives, prompt and candid evaluation, and resolution of issues at these early stages contribute to the accelerated growth. 


\section{Marketing the Home Therapies Program}

The first step in marketing is to establish a quality program. Managed care companies often restrict patients to use providers who are within a 30 -mile radius of their home or work. Therefore, this is a good area to target. Contact all nephrologists and key health care providers within that designated service area either through phone calls, personal contact or mailings. Brochures can be developed or established marketing materials can be placed in the offices of general/family practitioners and internists, particularly hypertensive specialists and endocrinologists, since these providers can be a major source of referrals. Pre-ESRD educational material and websites are also excellent means to increase awareness of treatment options. Acquiring or developing a database of phone numbers and addresses is one key to successful marketing. In addition to physicians, it should include nursing homes, hospitals, dialysis centers, home health agencies, geriatric case managers, managed care companies and other health care providers.

Marketing efforts are only as good as the product or service being offered. Listening to current customers is just as important as recruiting new ones. This two-way communication will not only help improve existing programs, it can help identify the public demand for profitable new services.

\section{The Fruits of Success}

A successful home program can improve the quality and extent of life for patients, reduces the cost of provision of therapy to society, reduces the demand for precious and scarce human resources (nursing shortage) and can be highly profitable to the provider, if properly structured. Like most great deeds, it requires knowledge, meticulous planning, capital investment and discipline. Certain circumstances, such as large distances to a dialysis center and the high cost of fully assisted dialysis, facilitate or even demand development of home dialysis centers. Conversely, the proliferation of dialysis centers in industrialized countries and in large urban areas, the high proportion of underutilized facilities in some regions competing with their development, and the lack of adequate education and exposure of young healthcare professionals in selected countries may interfere with these goals. Improvements in technology for both PD and HD, the recent introduction of specialized and dedicated equipment for home HD, the emphasis on frequent therapies and the proliferation of effective educational initiatives may be the catalysts for the growth and success of home programs.

\section{References}

1 Ahlmen J, Carlsson L, Schonborg C: Well-informed patients with end-stage renal disease prefer peritoneal dialysis to hemodialysis. Perit Dial Int 1993;13:S196-S198.

-2 Prichard S: Treatment modality selection in 150 consecutive patients starting ESRD therapy. Perit Dial Int 1996;16:69-72.

-3 Levin A, Lewis M, Mortiboy P, Faber S, Hare I, Porter EC, Mendelssohn DC: Multidisciplinary predialysis programs: quantification and limitations of their impact on patient outcomes in two Canadian settings. Am J Kidney Dis 1997;29:533-540.

4 Lameire N, van Biesen W, Dombros N, Dratwa M, Faller B, Gahl GM, Gokal R, Krediet RT, La Greca G, Maiorca R, Matthys E, Ryckelynck JPH, Selgas R, Walls J: The referral pattern of patients with ESRD is a determinant in the choice of dialysis modality. Perit Dial Int 1997;17(suppl 2):S161-S166.

-5 Little J, Irwin A, Marshall T, Rayner H, Smith S: Predicting a patient's choice of dialysis modality: experience in a United Kingdom renal department. Am J Kidney Dis 2001;37:981986.
6 Kidney Options Program: Therapy selection. Fresenius Medical Care North America, 2001. Data on file.

7 Stack AG: Determinants of modality selection among incident US dialysis patients: results from a national study. J Am Soc Nephrol 2002; 13:1279-1287.

8 Wuerth DA, Finkelstein SH, Schwetz O, Carey $\mathrm{H}$, Kliger AS, Finkelstein FO: Patient's descriptions of specific factors leading to selection of chronic peritoneal dialysis or hemodialysis. Perit Dial Int 2002;22:184-190.

9 Marron B, Ocana JCM, Salgueira M, Barril G, Lamas JM, Martin M, Sierra T, RodriguezCarmona A, Soldevilla A, Martinez F: Analysis of patient flow in dialysis: role of education in choice of dialysis modality. Perit Dial Int 2005; 25(suppl 3):S56-S59.

10 Mehrotra R, Blake P, Berman N, Nolph KD: An analysis of dialysis training in the United States and Canada. Am J Kidney Dis 2002;40: 152-160.
11 Nissenson AR, Agarwall R, Allon M, Cheung AK, Clark W, Depner T, Diaz-Buxo JA, Kjellstrand C, Kliger A, Martin KJ, Norris K, Ward $\mathrm{R}$, Wish $\mathrm{J}$ : Improving outcomes in CKD and ESRD patients: carrying the torch from training to practice. Semin Dial 2004;17:380-397.

12 Crawford-Bonadio TL, Forbes L, Pierre DS: Industry role in education - Meeting the demand. Adv Perit Dial 2004;20:121-124.

13 Winkelmayer WC, Weinstein MC, Mittleman MA, Glynn RJ, Pliskin JS: Health economic evaluations: the special case of end-stage renal disease treatment. Med Decis Making 2002; 22:417-430.

14 US Renal Data System, USRDS 2003 annual data report: atlas of end-stage renal disease in the United States. Bethesda, National Institutes of Health, National Institute of Diabetes and Digestive and Kidney Diseases, 2003.

15 Witten B, Schatell DR, Becker BN: Relationship of ESRD working-age patient employment to treatment modality (abstract). J Am Soc Nephrol 2004;15:633A.

16 Schatell D, Witten B: Dialysis patient empowerment: what, why and how. Nephrol News Issues $2005 ; 19: 37-39$. 